\title{
Dressler, Bernhard (2020). Religion verstehen. Beiträge zur Religionshermeneutik und zu religiöser Bildung. Stuttgart: Kohlhammer. ISBN 978-3-17-038 I62-9. 264 Seiten.
}

\author{
Ulrich Kropač \\ Katholische Universität Eichstätt-Ingolstadt (ulrich.kropac@ku.de)
}

Mit seinen Beiträgen zu Grundsatzfragen religiöser Bildung reiht sich Bernhard Dressler in eine seit den 1980erJahren von der evangelischen Religionspädagogik als Schrittmacher entwickelte Programmatik ein, religiöses Lehren und Lernen vom Begriff der Bildung her zu konzipieren. Diese Linie, für die prominente Namen wie Reiner Preul, Karl Ernst Nipkow, Peter Biehl, Godwin Lämmermann, Horst Rupp, Hans-Jürgen Fraas und Friedrich Schweitzer stehen, führt Dressler weiter, indem er religiöse Bildung in den Horizont des seit dem Jahr 2000 sich durchsetzenden bildungstheoretischen Paradigmenwechsels von der Input- zur Outcomeorientierung einrückt.

Die im vorliegenden Band zusammengetragenen Aufsätze sind - abgesehen von zwei Ausnahmen - allesamt schon früher in unterschiedlichen Organen (häufig den ZPT) veröffentlicht worden. Sie umspannen eine Schaffensperiode von ca. 20 Jahren. Die Sammlung soll, wie Dressler im Vorwort vermerkt, die Beiträge leichter zugänglich machen und „zugleich das, was man den ,roten Faden' meines theologischen und religionspädagogischen Denkens nennen könnte“ (7), deutlicher hervortreten lassen.

Die einzelnen Artikel widmen sich unterschiedlichen Themen, von denen die meisten aber darin übereinstimmen, dass es ,um Grundsätzliches‘ geht: Fragen nach Programm und Perspektiven der (evangelischen) Religionspädagogik, nach einem angemessenen (evangelischen) Verständnis religiöser Bildung, nach der Rolle von Kirche als Bildungsinstitution, nach den Aufgaben von Religionsunterricht und seinem Verhältnis zum Ethikunterricht. Eine kleinere Zahl von Artikeln ist speziellen Fragen gewidmet: So unterzieht Dressler den Diskurs zur Kindertheologie einer kritischen Sichtung, er stellt die verbreitete Auffassung, Religionsunterricht habe der Wertevermittlung zu dienen, auf den Prüfstand, unternimmt eine Kritik des Fortschrittsglaubens im Horizont religiöser Bildung, diskutiert das Verhältnis von Religion und Politik in Bildungsprozessen, sondiert die Relevanz und Reichweite empirischer Erkenntnisse für die religionspädagogische Theoriebildung und setzt sich mit religionssoziologischen Überlegungen Armin Nassehis auseinander.

In allen Artikeln wird ein Theoriegerüst erkennbar, von dem aus Dressler das jeweilige Thema bearbeitet. Dies dürfte der „,rote Faden“ sein, von dem im Vorwort die Rede ist. Das Theoriegerüst ist aus verschiedenen Bausteinen zusammengefügt: u. a. dem von Ernst Troeltsch übernommenen Gedanken der "Zusammenbestehbarkeit“ von Christentum und moderner Kultur (117 pass.), der Schleiermacherschen Formel, dass die christliche Religion im Doppelmodus von „Darstellung“ und „Mitteilung“ zu kommunizieren ist (109 pass.), der Idee, dass Bildung nicht auf Expertentum (bzw. Ausbildung), sondern gebildetes Laientum (d. h. die Fähigkeit, mit Expert*innen in Kommunikation zu treten) auszurichten ist (100 pass.), und dem Topos, dass sich die Tradierung der christlichen Religion „immer weniger in Form von Sozialisation, Konvention und organisatorischer Inklusion vollzieht, sondern [...] als Bildungsprozess“ (102 pass.). Diese Elemente werden in den größeren Rahmen des Baumertschen Schemas unterschiedlicher Modi der Welterschließung eingefügt. Das bildungstheoretische Programm, Bildung als Erschließung unterschiedlicher Rationalitätsmodi zu konzipieren, wird bei Dressler zu einer Didaktik des Perspektivenwechsels ausgefaltet, die interdisziplinär und intradisziplinär angelegt ist: interdisziplinär als Befähigung zur reflexiven Koordination unterschiedlicher Weltzugänge; intradisziplinär als Fähigkeit, dem Gegenstand Religion in einer Kombination von Beobachtung und Teilnahme bzw. Rede über Religion und religiöser Rede zu begegnen.

Das in den einzelnen Aufsätzen aufscheinende bildungstheoretische Konzept Dresslers ist in der Zwischenzeit vielfältig rezipiert worden, und zwar in der evangelischen und katholischen Religionspädagogik gleichermaßen. Es hat nicht weniger als ,maßgebenden' Charakter. Wer auch immer in den beiden konfessionellen religionspädagogischen communities über religiöse Bildung handelt, muss sich mit den Überlegungen Dresslers auseinanderset- 
zen: anknüpfend, modifizierend, distanzierend, fortschreibend ... Um auf den Sammelband zurückzukommen: Es ist nicht das Buch als Ganzes, das Maßstäbe setzt, sondern die einzelnen Artikel: Jeder spiegelt grundlegende Denkfiguren Dresslers. Die Stärke des Buches liegt, mit anderen Worten, nicht so sehr darin, dass seine Lektüre einen sukzessiven Wissens- und Erkenntniszuwachs für die Leser*innen erbrächte, sondern darin, dass sie es ihnen ermöglicht, ein bildungstheoretisches Grundmuster in unterschiedlichen thematischen Zusammenhängen wiederzuerkennen - was freilich gewisse inhaltliche Redundanzen unvermeidlich macht. Einen zusätzlichen Wert hätte der Band gewinnen können, wenn er noch mit diversen ,Lesehilfen' ausgestattet worden wäre: etwa einer Einleitung, die einen kurzen Überblick über die einzelnen Artikel gibt, einem Personenverzeichnis, in dem von Dressler häufig zitierte Gewährsleute (wie z. B. H. Arendt, J. Habermas, N. Luhmann, F. Schleiermacher, E. Troeltsch) genannt werden, einem Ausblick über anstehende religionspädagogische Weiterentwicklungen etc. Dann wäre das Buch mehr geworden als ein Sammelband, ein Werk nämlich, das hilft, Dresslers religionshermeneutisches und bildungstheoretisches Konzept systematisch zu erschließen.

Basal für die Dresslersche Theorie religiöser Bildung ist eine Dialektik des Perspektivenwechsels zwischen Innenund Außerperspektive. Der Rezensent erlaubt es sich, mit dieser Denkfigur an das zu besprechende Buch heranzugehen und zu einer protestantischen Theorie religiöser Bildung einige Beobachtungen aus einer katholischen Außenperspektive beizusteuern. Einem solchen Blick fällt auf: Katholische Beiträge zu religiöser Bildung werden von Dressler kaum verarbeitet, die Verweise in den Fußnoten bewegen sich, soweit es sich um theologische und religionspädagogische Fragen handelt, weitestgehend im protestantischen Bereich. Da das Denken Dresslers deutlich in der protestantischen Tradition verankert ist, hätte die belegte Auseinandersetzung mit anderen theologischen und religionspädagogischen Denkweisen - in erster Linie der katholischen - einen Zugewinn an Perspektivität und damit auch an Profil erbringen können. Konkret: Auffällig ist beispielsweise, dass bei der Symboldidaktik zwar u. a. P. Biehl, M. Meyer-Blanck, B. Dressler und Th. Klie genannt werden (9) - aber kein katholischer Religionsdidaktiker. Anderes Beispiel: Zu Recht weist Dressler darauf hin, dass die Unterscheidung von Religion und Glaube für religiöse Bildungsprozesse konstitutiv ist. Glaube wird - protestantischer Theologie und Tradition entsprechend als ein „als Gottesverhältnis gedeutetes je individuelles Selbstverhältnis“ (85f.) bestimmt. Zumindest einen Hinweis hätte es geben können, dass die Schwestertradition hier noch einen anderen Akzent setzt, indem sie den individuellen Glauben mit dem Glauben einer Gemeinschaft (,Kirche') verschränkt denkt. Letztes Beispiel: Evangelische und katholische Religionsdidaktik stimmen darin überein, dass zu religiöser Kompetenz Partizipationskompetenz gehört. Bei Dressler wird Partizipation ausschließlich als experimentelle, probeweise Teilnahme (57 pass.) gedacht. Die katholische Religionsdidaktik (z. B. H. Mendl) geht hier einen anderen Weg, ohne deswegen das untaugliche Modell einer ,Kirche in der Schule‘ wiederbeleben zu wollen. Im Übrigen dürfte der Religionsunterricht der Primarstufe in der Praxis nicht selten näher an ein ,learning in religion' heranrücken, als das die religionsdidaktische Theorie eigentlich erlauben würde. Allgemeiner gesprochen: Die stärkere Berücksichtigung der je anderen konfessionellen Außenperspektive ist für die religionspädagogische Theoriebildung nicht nur wissenschaftstheoretisch geboten, sondern auch aus ökumenischen Gründen indispensabel.

Fazit: Bernhard Dressler hat mit seinen Reflexionen den Diskurs um religiöse Bildung um einen wesentlichen Beitrag bereichert. Es steht zu erwarten, dass sein Denken in der gegenwärtigen Debatte um die Zukunft des Religionsunterrichts weiterhin eine unverzichtbare Referenzgröße darstellt. Der Sammelband erlaubt es, aus diesem Fundus reichlich zu schöpfen. 